\title{
Plant biodiversity hotspots mapping and prioritization in the Bulgarian floristic region Eastern Balkan Mountains
}

\author{
Stoyan Vergiev* \\ Department of Ecology and Environmental Protection, Technical University of Varna, Varna, Bulgaria.
}

GSC Biological and Pharmaceutical Sciences, 2021, 17(01), 061-066

Publication history: Received on 30 August 2021; revised on 04 October 2021; accepted on 060 ctober 2021

Article DOI: https://doi.org/10.30574/gscbps.2021.17.1.0295

\begin{abstract}
The main goal of the present study was to create a dynamic map of plant biodiversity hotspots of the Bulgarian floristic region Eastern Balkan Mountains. A GIS model, as well as a weighted value scheme for scoring each area, were created in order to identify and to prioritize the hotspots. A total number of defined hot spots of phytodiversity was 34 . They were categorized into five classes, based on the cumulative weighted value scheme, and were indicated on the map using color scale. The territories into category I predominated, contrary to preceding investigations of the Black Sea coast and northeastern Bulgaria where category $\mathrm{V}$ predominated. In addition, an attempt to refine the borders of the floristic region was made.
\end{abstract}

Keywords: Biodiversity hotspots; Floristic region; Eastern Balkan Mountains; Geographic information system (GIS)

\section{Introduction}

Holistic approach of biodiversity management is based on loss reduction under limited financial and human resources [1]. Therefore, fundamental task of conservation biology is species and their habitats identification and prioritization [2] in order to focus limited public financial resources to the most endangered species and areas [1, 3].

In recent years, the newly developed evaluation systems for identification and prioritization of conservation territories, unlike the classical models for conservation significance are based on cumulative criterion schemes for identification and assessment of dynamic areas $[2,4,5]$.

The hotspot approach is based on biodiversity indicators [3, 6], which identify geographical areas characterized by high species diversity, high concentration of endemic species, and high risk of habitat loss [7]. Although, the concept of plant biodiversity hotspots was created for global use $[8,9,10]$, it can be applied in local and regional scale after improvement [11]. Local hot spots conception is useful tool for assessing the vulnerability of habitats, annual monitoring, distribution and protection of plants, as well as for the creation of long-term strategies for development and protection of phytoresources and habitats [12].

Clearly and precisely formulated evaluation criteria of the assessments are reliable base for developing GIS-based models, which comprise dynamic geographical maps of habitats with assessment scale and associated numerous data sets [13]. Based on this concept, a regional assessment scale can be created in order to identify hot spots of local phytodiversity. This model as well as local assessment scheme were applied for the floristic subregions of the Black Sea coast $[2,4,6]$.

\footnotetext{
* Corresponding author: Stoyan Vergiev

Department of Ecology and Environmental Protection, Technical University of Varna, Varna, Bulgaria.

Copyright (@ 2021 Author(s) retain the copyright of this article. This article is published under the terms of the Creative Commons Attribution Liscense 4.0.
} 
The aims of the present study were 1) to prepare a map of hot spots of plant biodiversity for the floristic region Eastern Balkan Mountains and 2) to develop a regional scheme for assessment, classification, and prioritization of natural areas based on the concept of hot spots of plant biodiversity.

\section{Material and methods}

The studies of the spatial distribution of the plant communities were based on literature data of the distribution of plant species in the study area $[14,15,16,17,18,19,20]$ and were detailed and refined with data from field observations and remote sensing during the vegetation period of 2021.

Conservation status, as well as endemics and relics were determined after [15, 16, 21, 22, 24, 25].

A regional plant species assessment scheme based on the concept of plant biodiversity hotspots was used. The summarized scheme, based on 3 groups of criteria that comprise the distribution and conservation status of plant taxa is presented in Table 1 [6].

Table 1 Summary scheme of criteria for the assessment of plant taxa [6]

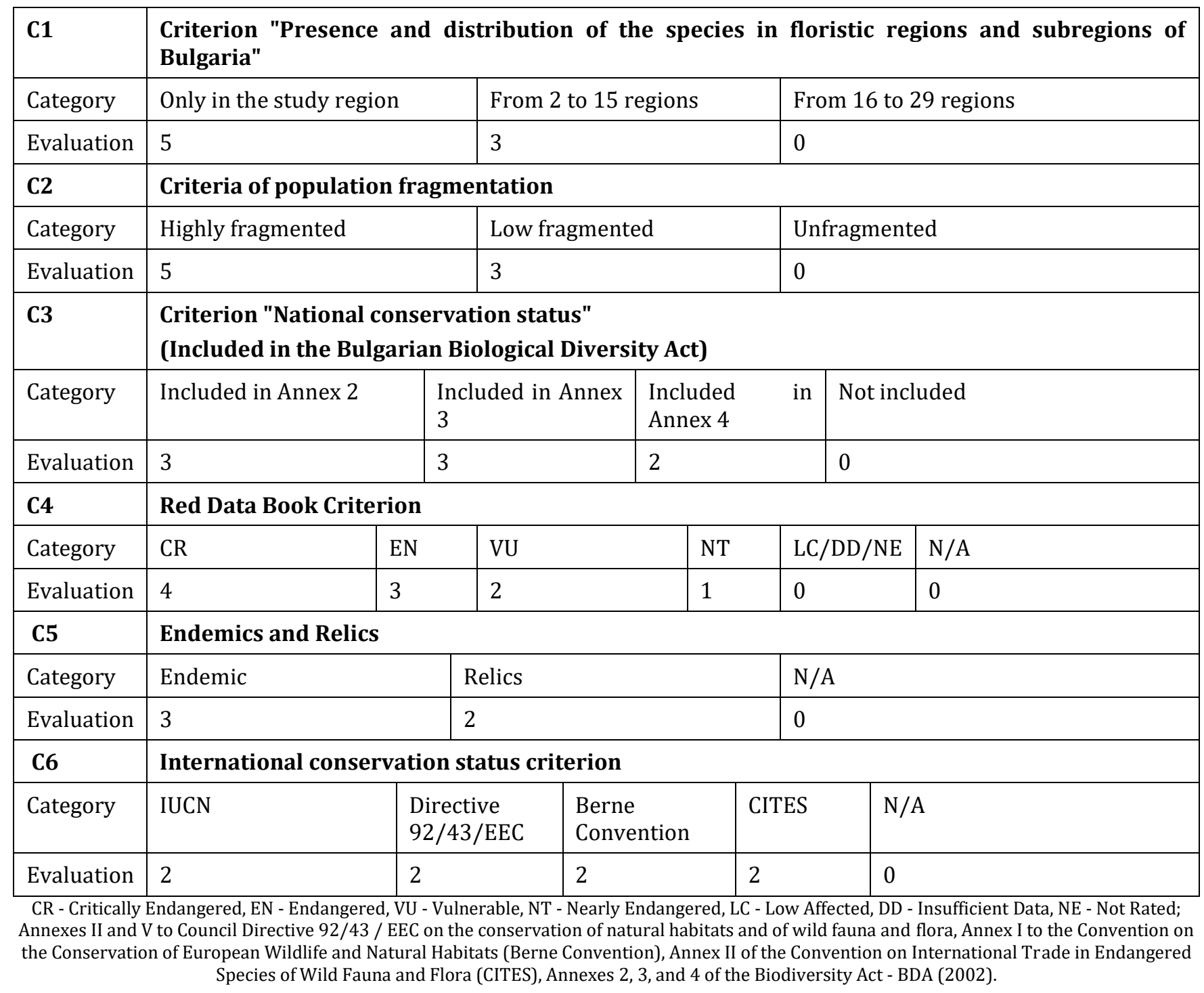

The evaluation of each individual taxon was obtained as the sum of the points of each of the criteria, after applying the relevant coefficients of significance of the criterion according to the formula:

$$
A_{i}=0,5 x C 1_{i}+0,5 x C 2 i+1,25 x C 3_{i}+1 \times C 4 i+1,25 x C 5 i+1,5 x C 6 i
$$


where,

$\mathrm{A}_{\mathrm{i}}$ - general assessment of the taxon $\mathrm{i}$

$\mathrm{C} 1_{\mathrm{i}}-\mathrm{C} 6_{\mathrm{i}}$ - estimates by criteria $\mathrm{C} 1$ to $\mathrm{C} 6$ for taxon $\mathrm{i}$.

In order to map hotspots, a dynamic GIS-based model was built and was applied using the Model Builder module of ArcView Spatial Analyst (ArcGIS v.10.0 ESRI Inc.). The model was designed to identify and to estimate the areas with a concentration of species and the places of overlap of the polygons of their distribution. The general assessment of each polygon was calculated according to the formula:

$$
E=\frac{\sum_{k=1}^{n} A n}{n}
$$

where,

E - general assessment of the territory

A - assessment of each individual taxon

$\mathrm{n}$ - total number of assessed taxa in the territory.

When drawing the maps, the following were used: UTM Zone 35 North map projection, WGS84 terrestrial coordinate system and the Baltic altitude system. The collected field and remote sensing data were organized in attribute tables and assigned to the layers in vector format using relational classes in a GIS environment using base maps and Digital Terrain Model (DTM).

\section{Results and discussion}

The identification of hot spots is based on an adequate inventory of the flora the study area [26]. For this purpose, a list of flora was prepared based on literature data, as well as unpublished own studies. The established total number of plant species found in the region was 1723.785 of them had a score of 0 points. Only the species that can be defined as indicators of biodiversity for the territory of Bulgaria were included in the study (they had a score higher than 0 points). For the floristic region of Eastern Balkan Mountains their number is 938 or $54.43 \%$ of the total established taxa. Comparing to previous studies, these values are higher than floristic region North-Eastern Bulgaria [26], and consistent with data from the subregions of Bulgarian Floristic region Black Sea Coast $[2,4,6]$.

The borders of the floristic region of Eastern Balkan Mountains were defined after the Flora of Bulgaria [15, 18, 19]. Based on some geographical characteristics, an attempt to refine the border of the floristic subregion was made.

\begin{tabular}{|c|c|c|c|c|}
\hline \multicolumn{3}{|c|}{ Less species diversity } & \multicolumn{2}{|c|}{ Higher species diversity } \\
\hline Low risk & & & & High risk \\
\hline $\mathrm{V}$ & IV & III & II & $\mathrm{I}$ \\
\hline$<39$ points & $40-75$ points & 76 - 99 points & $100-128$ points & $>129$ points \\
\hline
\end{tabular}

Figure 1 Generalized weight scheme in 5 classes and their color representation

The used model is designed to integrate a regional scheme for prioritization. Preceding investigations and analyzes of the Black Sea coast [6,27] and northeastern Bulgaria [26] showed that the classes of hot spots have similar values in different regions. Taking into account that the flora and vegetation of the floristic regions in Bulgaria differ, the assessment of each class was as a percentage of the maximum assessment for each territory. Based on this, all five categories of hotspots were identified (Figure 1). 
Applying the constructed model and as a result of the "overlay" analysis, all values within the areas of overlap of the polygons were summarized and the hot spots of the biodiversity were determined (Table 2).

Table 2 Number of defined hotspots

\begin{tabular}{|c|c|c|c|c|c|}
\hline \multicolumn{5}{|c|}{ Category } & \multirow{2}{*}{ Total number } \\
\cline { 1 - 4 } I & II & III & IV & V & \\
\hline 17 & 2 & 4 & 5 & 6 & 34 \\
\hline
\end{tabular}

Detailed maps of the biodiversity hotspots for the floristic region Eastern Balkan Mountains in GIS environment were drawn (Figure 2). As a result of the prepared map, the border of the floristic area was refined.

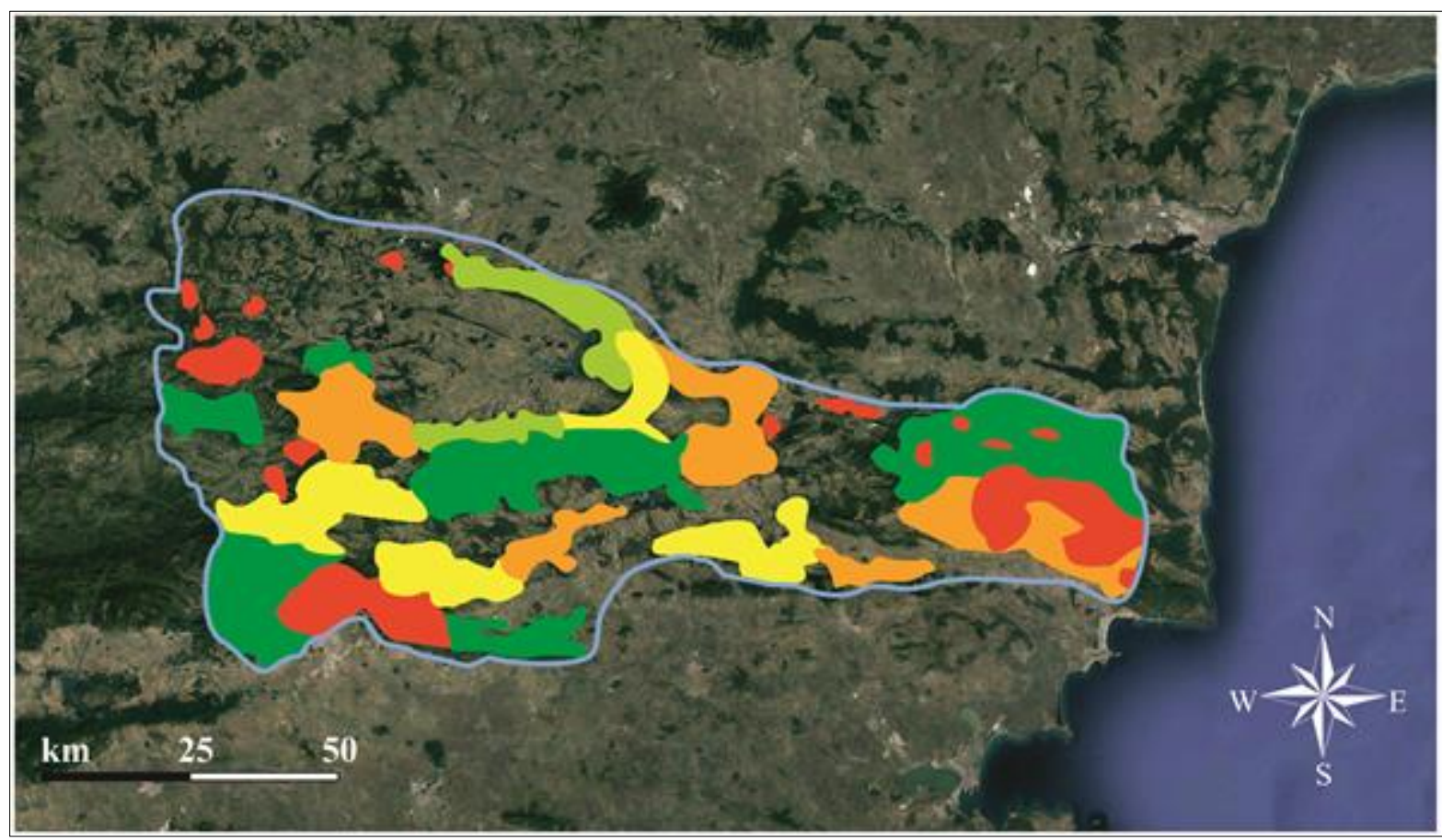

Figure 2 Map of the hot spots of biodiversity in the floristic region of Eastern Balkan Mountains (Base map: Google Earth 2017, TerraMetrics; CNES / Airbus)

The total number of defined hot spots of phytodiversity in the floristic region Eastern Balkan Mountains was 34 . The territories into category I predominated, contrary to preceding investigations of the Black Sea coast [6, 27] and northeastern Bulgaria [26] where category V predominated.

\section{Conclusion}

The total number of defined hot spots of phytodiversity in the floristic region Eastern Balkan Mountains was 34 . The territories into category I predominated.

\section{Compliance with ethical standards}

\section{Acknowledgments}

A part of the scientific research, the results of which are presented in this article, was conducted at Technical University of Varna, within the framework of the scientific research, funded by the state budget. 


\section{Disclosure of conflict of interest}

The authors declare the absence of a conflict of interest.

\section{References}

[1] Watson J., Evans MC, Carwardine J, Fuller RA, Joseph LN, Segan, DB, Taylor MF, Fensham RJ, Possingham HP. The capacity of Australia's protected-area system to represent threatened species. Conservation Biology. 2011; 25(2): 324- 332.

[2] Vergiev S. GIS mapping of plant biodiversity hotspots in the Bulgarian Floristic region Black Sea Coast. SocioBrains. 2018; 52: 172-178.

[3] Primak R, Uzunov Y, Georgiev B. Conservation biology. Sofia: Pensoft. 2018.

[4] Vergiev S, Niyazi D, Filipova-Marinova M. GIS mapping of plant biodiversity hotspots in the Bulgarian floristic region Southern Black Sea coast. Proceedings of the 5th SSC "Ecology and environment. 2017; 47-55.

[5] Haydu K. Mapping Plant Biodiversity Hotspots at the County Scale: A New Tool for Establishing Resource Conservation Strategies [Ph.D. dissertation]. San Luis Obispo: Cal Poly State University. 2012.

[6] Vergiev S. GIS mapping of plant biodiversity hotspots in the Bulgarian floristic region Northern Black Sea Coast for 2018. SocioBrains. 2019; 54: 196-201.

[7] Myers N. Threatened biotas: "hotspots" in tropical forests. The Environmentalist. 1988; 8(3): 187-208.

[8] Mittermeier RA, Myers N, Thomsen JB, da Fonseca GA, Olivieri S. Biodiversity hotspots and major tropical wilderness areas: Approaches to setting conservation priorities. Conserv. Biol. 1998; 12: 516-520.

[9] Myers N. The biodiversity challenge: expanded hot-spots analysis. The Environmentalist. 1990; 10(4): 243-256.

[10] Myers N, Mittermeier RA, Mittermeier CG, da Fonseca GA, Kent J. Biodiversity hotspots for conservation priorities. Nature. 2000; 403: 853-858.

[11] Williams KJ, Ford A, Rosauer D, De Silva N, Mittermeier R, Bruce C, Larson FW, Margules C. Forests of East Australia: the 35th biodiversity hotspot. In: Zachos FE, Habel JC, eds. Biodiversity Hotspots: Distribution and Protection of Conservation Priority Areas. Baden-Württemberg: Springer; 2011.

[12] Vergiev S. The impact of sea water immersion on the viability of psammophilous species Carex colchica and its capacity as dune stabilizer. Comptes Rendus de l'Academie Bulgare Des Sciences. 2017; 71(5): 648-654.

[13] Salem BB. Application of GIS to biodiversity monitoring. Journal of Arid Environments. 2003; 54: 91-114.

[14] Kitanov B. Vegetation. Sofia: Prof. M. Drinov Acad. Publ. 1976.

[15] Asyov B, Petrova A, Dimitrov D, Vasilev R. Conspectus of the Bulgarian vascular flora. Distribution maps and floristic elements. Sofia: Bulgarian Biodiversity Foundation. 2012.

[16] Peev D. Main ed. Red Data Book of Republic of Bulgaria. 1. Plants and Fungi. Sofia: IBER - BAS \& MEW. 2011.

[17] Jordanov D. Flora of the Republic of Bulgaria. Vol. 1-9. Sofia: Prof. M. Drinov Acad. Publ. 1963-1979.

[18] Kozhuharov S. Flora of the Republic of Bulgaria, Vol. 10. Sofia: Prof. M. Drinov Acad. Publ. 1995.

[19] Peev D. Flora of the Republic of Bulgaria, Vol. 11. Sofia: Prof. M. Drinov Acad. Publ. 2013.

[20] Bondev I. Vegetation of Bulgaria. Map M 1:600 000. Sofia: Prof. M. Drinov Acad. Publ. 1991.

[21] The Council of the European Communities. Council Directive 92/43/EEC on the Conservation of Natural Habitats and of Wild Fauna and Flora. Official Journal of the European Union. 1992; 206: 7-50.

[22] International Union for Conservation of Nature. UCN Red List of Threatened Plants [Internet]. Gland: International Union for Conservation of Nature. 2021.

[23] International Union for Conservation of Nature. Convention on International Trade in Endangered Species of Wild Fauna and Flora. Washington: International Union for Conservation of Nature. 1973.

[24] National Assembly of the Republic of Bulgaria. Biodiversity Act. State Gazette. 2002; 77: 9-42. 
[25] Peev D, Kozuharov St, Anchev M, Petrova A, Ivanova D, Tzoneva S. Biodiversity of Vascular Plants in Bulgaria. In: Meine C, ed. Bulgaria's Biological Diversity: Conservation Status and Needs Assessment, Volumes I and II. Washington: Biodiversity Support Program. 1998.

[26] Vergiev S. Identification, prioritization, and GIS mapping of plant biodiversity hotspots in the Bulgarian Floristic Region North-eastern Bulgaria. Socio Brains. 2021; 84: 78-83.

[27] Vergiev S. Comparative Study of the Response of Four Native to the Bulgarian Black Sea Coast Psammophytes to Simulated Flooding Experiments. Annual Research \& Review in Biology. 2017; 16(1): 1-8. 